\title{
Iniciação infantil ao polo aquático: fundamentação teórica e proposta de atividades
}

\section{Children's initiation to the water polo: theoretical foundation and proposal of activities}

\section{Iniciación infantil al polo acuático: fundamento teórico y propuesta de actividades}

(iD) Dieisson Machado Vasques

Universidade Federal do Rio Grande do Sul - Porto Alegre, Rio Grande do Sul, Brasil e-mail: dieissonvasques@gmail.com

iD (9) Diego Andrades Paixão

Universidade Federal do Rio Grande do Sul - Porto Alegre, Rio Grande do Sul, Brasil e-mail: diego.paixao@ufrgs.br

iD Flávio Antônio de Souza Castro

Universidade Federal do Rio Grande do Sul - Porto Alegre, Rio Grande do Sul, Brasil e-mail: souza.castro@ufrgs.br

Resumo: Este estudo tem por objetivo propor diretrizes teórico-práticas para a construção de metodologias de ensino do Polo Aquático (PAq). Pretende apontar conteúdos indispensáveis na iniciação ao PAq para crianças (6 a 10 anos de idade) e apresentar atividades práticas para o processo de ensino-aprendizagem através de uma revisão narrativa de materiais pertinentes ao tópico na forma de ensaio. Clareza de linguagem, pertinência prática e representatividade do item foram avaliados por três especialistas e o coeficiente de validade de conteúdo geral foi de 0,91. A proposição de atividades baseadas em referenciais teóricos pode guiar os profissionais de educação física a ampliar o leque pedagógico de maneira sólida.

Palavras-Chave: Esportes Aquáticos. Pedagogia. Método Situacional. 


\begin{abstract}
This study aims to propose theoretical and practical guidelines for the construction of a teaching methodologies for Water Polo (PAq). It intends to point out indispensable contents in the initiation to PAq for children (6 to 10 years old) and to present practical activities for the teaching-learning process through a narrative review of materials pertinent to the topic in the form of an essay. Clarity of language, practical relevance and representativeness of the item were assessed by three experts and the overall content validity coefficient was 0.91 . The proposition of activities based on theoretical references can guide physical education professionals to expand the pedagogical range in a solid way.
\end{abstract}

Keywords: Water Sports. Teaching. Situational Method.

Resúmen: Este estudio tiene como objetivo proponer pautas teóricas y prácticas para la construcción de metodologías de enseñanza para Water Polo (PAq). Busca señalar contenidos indispensables en la iniciación a PAq para niños (6 a 10 años) y presentar actividades prácticas para el proceso de enseñanza-aprendizaje a través de una revisión narrativa de materiales pertinentes al tema en forma de ensayo. Tres expertos evaluaron la claridad del lenguaje, la relevancia práctica y la representatividad del ítem y el coeficiente de validez de contenido general fue 0,91. La propuesta de actividades basadas en marcos teóricos puede orientar a los profesionales de la educación física a ampliar enormemente el abanico pedagógico.

Palabras clave: Deportes Acuáticos. Enseñanza. Método Situacional.

Submetido em: 23-03-2021

Aceito em: 26-03-2021 


\section{Introdução}

O polo aquático (PAq) é um esporte de invasão em um contexto de imprevisibilidade, subjetividade, variabilidade e pouca estabilidade ambiental devido ao meio aquático (LAMAS et al., 2014; GONZÁLEZ et al., 2017). Exige permanente adaptação motora (BAYER, 1994; GONZALEZ, 2004; GALLATI, 2017). É de alta complexidade, exigência física, técnica, psicológica e, ainda, de característica intermitente (SMITH, 1998). O domínio das habilidades e competências aquáticas é premissa básica para a participação no jogo (CANOSSA et al., 2009).

As atividades aquáticas, assim, devem proporcionar condições para que o aluno explore as muitas possibilidades de movimento na água e adquira o domínio dessas habilidades (FIORI et al., 2019). A manipulação da bola não pode ser separada do processo de adaptação ao meio aquático, assim como os arranques, mudanças de direção, ritmo, saltos, rotações e técnica específica de pernada (eggbeater) também devem fazer parte dos planos de aulas (CANOSSA et al., 2009). Dentre os aspectos coletivos, os princípios para ação ofensiva/defensiva (GALATTI, 2017), contra-ataques e situações de superioridade numérica temporal (TUCHER et al., 2014) merecem destaque. Ainda, para o melhor processo de ensino-aprendizagem, é necessário observar as fases do desenvolvimento motor da criança (GALLAHUE et al., 2013).

Em países com PAq mais desenvolvido, o processo de iniciação ocorre antes dos 10 anos de idade (CLÉMENÇON, 1989; SARMENTO, 1995). No Brasil, existem poucos e localizados projetos de iniciação ao PAq, o que parece dificultar a popularização, formação de atletas e, consequentemente, a renovação no esporte. A carência na formação de profissionais habilitados, talvez motivada pela escassez no campo teórico, também contribui para que o PAq ainda seja um esporte pouco difundido no país. Até o presente, não foram encontrados referenciais específicos para a iniciação infantil ao PAq. 
Desse modo, o presente estudo descreve atividades práticas para a iniciação ao PAq. A escolha da faixa etária entre 6 e 10 anos se justifica por ser um período relevante para o desenvolvimento multilateral e aquisição motora variada, com consequente alargamento do repertório motor (CANOSSA et al., 2007; GALLAHUE et al., 2013). Sendo assim, este ensaio tem como objetivo geral propor diretrizes teórico-práticas para a construção de metodologias de ensino do PAq. Como objetivo específico, este estudo apresenta atividades práticas para o processo de ensino-aprendizagem do PAq.

\section{Referencial teórico}

A adaptação ao meio aquático (AMA) é a base para a iniciação de todos os esportes aquáticos (CASTRO, CORREIA e WIZER, 2016). Entretanto, o foco da maior parte das publicações sobre a AMA está no ensino da natação (CATTEAU e GAROFF, 1990; PALMER, 1990). A AMA deve englobar o domínio de todas as possibilidades de movimento no meio aquático, a fim de que o indivíduo possa desfrutar desse meio para seus interesses particulares, que podem estar no campo do lazer, da reabilitação, da saúde, da competição, da arte, entre outros (FERNANDES e LOBO DA COSTA, 2006). O PAq exige que o praticante tenha o domínio do seu corpo no meio aquático, tanto para sustentação, quanto para os deslocamentos (SILVA, GIULIANO e CASTRO, 2016). Além disso, para o PAq, deve-se considerar as competências inerentes à prática dos esportes coletivos, tais como estratégia, tática e técnica (GRECO, 2012).

Referenciais teóricos que tenham como base o desenvolvimento de habilidades, atividades coordenativas e jogos situacionais voltados aos esportes coletivos de invasão (KRÖEGER et al., 2002; LAMAS et al., 2014; GONZÁLEZ, DARIDO e OLIVEIRA, 2017) são imprescindíveis para o desenvolvimento do PAq. Os princípios de jogo do PAq devem ser incluídos desde a iniciação (CANOSSA et al., 2009). Entretanto, essas informações precisam ser distribuídas 
Iniciação infantil ao polo aquático: fundamentação teórica e proposta de atividades Dieisson Machado Vasques • Diego Andrades Paixão • Flávio Antônio de Souza Castro

de acordo com as fases do desenvolvimento motor das crianças (GALLAHUE et al., 2013; FREIRE, 2015).

\section{Métodos}

Esta proposta para iniciação ao PAq foi realizada em duas etapas:

i. Seleção de atividades tendo por base literatura relativa à AMA (CATTEAU e GAROFF, 1990; PALMER, 1990) e com referências ao PAq (CANOSSA et al., 2009; CASTRO, WIZER e CORREIA, 2016);

ii. Clareza de linguagem (CL), pertinência prática (PP) e representatividade do item (RI) foram avaliados por três especialistas (professores de educação física, com doutorado e experiência nas áreas da iniciação aos esportes aquáticos) e utilizadas para o cálculo do Coeficiente de Validade de Conteúdo (CVC) das atividades (HERNÁNDEZ-NIETO, 2011). Foram utilizadas as médias dos especialistas para cada item, o erro considerando três avaliadores $(=0,03)$, e as médias finais de cada item. Valores acima de 0,7 foram considerados aceitáveis (CASSEPP-BORGES, BALBINOTTI e TEODORO, 2010). Este processo foi realizado em três etapas: (i) em uma planilha eletrônica, após explicação dos objetivos da lista de atividades, os especialistas pontuaram cada item em relação à CL, PP e RI com uma escala do tipo Likert, atribuindo de 1 (pouquíssimo claro; pouquíssimo pertinente; pouquíssimo representativo para a iniciação ao polo aquático) a 5 (muitíssimo claro; muitíssimo pertinente; muitíssimo representativo para a iniciação ao polo aquático) e, quando necessário, teceram comentários em cada um dos itens. (ii) De posse dessa primeira versão atualizada, os autores calcularam os valores prévios de CVC (variaram de 0,63 a 0,93) e geral $\left(C V C_{t}=0,86\right)$, revisaram e refizeram algumas atividades. (iii) A nova lista, com as correções, 
foi novamente enviada para os especialistas que fizeram nova rodada de avaliação. Desta rodada foram calculados os valores finais de CVC para CL, PP e RI para cada tarefa e geral.

\section{A Iniciação esportiva no PAq: construção teórica}

A abordagem multidisciplinar na AMA pode permitir ao praticante desenvolver uma base motora geral, assim como competências motoras aquáticas que alicerçam e facilitam a aprendizagem e desenvolvimento de habilidades mais específicas do PAq (CANOSSA et al., 2007). Dentre os conteúdos básicos, destacam-se as técnicas propulsivas específicas, aspectos técnicos e tático-técnicos (CANOSSA et al., 2009).

A técnica pode ser definida como a habilidade de executar uma tarefa da maneira mais objetiva e econômica possível (WEINECK, 1999). As técnicas propulsivas indispensáveis ao jogador de PAq são o eggbeater (sustentação vertical), arranque/travagem, crawl polo, drible, rotações, saltos, giros, mudanças de direção e sentido de nado (CANOSSA et al., 2009). Os aspectos técnicos do PAq incluem a recepção, passe e arremesso da bola (CANOSSA et al., 2009). Já a tática é definida como a gestão do espaço de jogo em adaptação constante à oposição adversária (RIERA, 1995). Os conteúdos tático-técnicos do PAq são constituídos pelo regulamento do jogo, que norteia as ações: posições básicas de defesa e ataque, recepção, passe e defesa com oposição, meios táticos ofensivos e defensivos e as ações do goleiro (CANOSSA et al., 2007; GALATTI, 2017).

Com o intuito de contemplar a iniciação do PAq por meio de jogos situacionais, desenvolvimento das capacidades coordenativas e das habilidades das crianças de acordo com as respectivas fases do desenvolvimento motor, este ensaio busca trazer alternativas ao ensino deste esporte de invasão (KRÖGER et al., 2002; GALLAHUE et al., 2013; GONZÁLEZ, DARIDO e OLIVEIRA, 2017). Por outro lado, a simples transferência desse conhecimento para o en- 
Iniciação infantil ao polo aquático: fundamentação teórica e proposta de atividades Dieisson Machado Vasques • Diego Andrades Paixão • Flávio Antônio de Souza Castro

sino do PAq não seria eficiente. É fundamental que as características biomecânicas da água sejam consideradas (arrasto, pressão hidrostática, empuxo), já que impõem um grau de dificuldade aos deslocamentos que não ocorrem no meio terrestre (FIORI et al., 2019; CASTRO, CORREIA e WIZER, 2016).

Apesar do aspecto maturacional se sobrepor à idade cronológica (SCHNEIDER e MEYER, 2005), de maneira geral, crianças entre 6 e 8 anos estão inseridas no estágio de proficiência motora, no qual apresentam performances eficientes e controladas referentes às habilidades fundamentais do movimento. Já as crianças entre 8 e 10 anos estão iniciando o estágio de transição para a fase do movimento especializado, no qual teriam condições de aplicar as habilidades básicas adquiridas com maior precisão, controle e combinações de padrão de movimento (GALLAHUE et al., 2013). Somado a isso, a faixa etária compreendida entre 6 e 10 anos é o período no qual as atividades lúdicas e jogos com regras adaptadas geram maior engajamento das crianças com a iniciação ao esporte (BAKER e COTÊ, 2003).

Respeitando as fases do desenvolvimento motor dos iniciantes no PAq, consideramos que o aluno deve participar ativamente da construção do processo do conhecimento, sendo constantemente estimulado à reflexão pelo professor (FREIRE, 2015). O papel do professor deve ser também de estimular, desafiar, despertar sua curiosidade como motivação para seguir aprendendo. De maneira prática, o contexto da iniciação ao PAq está relacionado à construção do conhecimento tático e solução de problemas inerentes às situações de jogo por parte do jogador. A criança deve ter autonomia para tomar decisões durante as atividades, utilizando o repertório que adquiriu ao longo do processo de ensino-aprendizagem.

\section{Da teoria à prática: a transferência para a piscina}

Os conteúdos descritos a seguir buscam enriquecer o repertório motor das crianças para que possam jogar de forma plena e, paralelamente, desenvolver o entendimento tático do jogo. 
Além disso, desenvolver a capacidade de antecipação e tomada de decisão, atitudes e valores fundamentais para a prática do PAq (BAELLA e LLORET, 1996). Assim, as aulas poderiam ser compostas por (i) atividades de AMA; (ii) atividades técnicas e (iii) atividades tático-técnicas.

\section{Atividades de AMA}

Assumindo que o ser humano não é um ser aquático, é necessário que nele sejam desenvolvidas funções motoras básicas neste meio, tais como respiração, equilíbrio e propulsão (FERNANDES e LOBO DA COSTA, 2006). As características físicas da água determinam distintos comportamentos motores quando comparados ao meio terrestre, devido às forças que restringem as interações do corpo com o meio (CASTRO, CORREIA e WIZER, 2016). Todas as atividades listadas a seguir devem considerar profundidade adequada à criança ficar em pé, com segurança, e, quando usar bola, esta deve ser de dimensões adequadas à criança.

\section{Respiração, imersão e equilíbrio}

A sequência de atividades descritas no presente estudo está associada ao grau de experiência da criança no meio aquático. Entretanto, a criatividade do professor, em relação à ludicidade na aplicação dos exercícios, poderá ser fator decisivo na adesão às aulas de PAq. Os quadros a seguir apresentam as atividades propostas bem como os resultados de clareza de linguagem, pertinência prática e representatividade do item e coeficiente de conteúdo total do item. No Quadro 1, as atividades iniciais da AMA. 
Iniciação infantil ao polo aquático: fundamentação teórica e proposta de atividades Dieisson Machado Vasques • Diego Andrades Paixão • Flávio Antônio de Souza Castro

\section{Quadro 1 - Atividades para desenvolvimento da imersão, da respiração e do equilíbrio}

\begin{tabular}{|c|c|c|c|c|}
\hline Posição em pé & CL & PP & RI & CVCt \\
\hline $\begin{array}{l}\text { 1. Com o auxílio das mãos em forma de concha, levar a água ao } \\
\text { rosto e molhá-lo }\end{array}$ & 0,90 & 0,83 & 0,70 & 0,81 \\
\hline $\begin{array}{l}\text { 2. Realizar expirações completas contra a água colocada nas } \\
\text { mãos, parcialmente submersas, próximas à superfície }\end{array}$ & 0,96 & 0,83 & 0,83 & 0,87 \\
\hline $\begin{array}{l}\text { 3. Imergir o rosto com os olhos abertos, braços estendidos à } \\
\text { frente do corpo e mãos espalmadas sobre a superfície da água } \\
\text { (a fim de proporcionar maior apoio) }\end{array}$ & 0,96 & 0,96 & 0,83 & 0,92 \\
\hline $\begin{array}{l}\text { 4. A partir da posição inicial do exercício anterior, com o rosto } \\
\text { submerso, expirar de diferentes maneiras: constante, pausa- } \\
\text { do, bucal, nasal, combinações }\end{array}$ & 0,90 & 0,96 & 0,83 & 0,90 \\
\hline \multicolumn{5}{|l|}{ Diferentes posições } \\
\hline $\begin{array}{l}\text { 5. Realizar deslocamentos caminhando pela piscina em diferen- } \\
\text { tes direções (frente, costas, lateral) e diferentes velocidades } \\
\text { (caminhar, correr, saltar) }\end{array}$ & 0,96 & 0,96 & 0,76 & 0,90 \\
\hline $\begin{array}{l}\text { 6. Realizar mergulhos na vertical (canguru), sem e com desloca- } \\
\text { mento, seguido de mergulhos na horizontal (baleia) com des- } \\
\text { locamento }\end{array}$ & 0,96 & 0,96 & 0,83 & 0,92 \\
\hline $\begin{array}{l}\text { 7. Explorar trocas de direção nos mergulhos vertical e horizontal } \\
\text { descritos na atividade anterior }\end{array}$ & 0,83 & 0,96 & 0,83 & 0,87 \\
\hline $\begin{array}{l}\text { 8. Realizar flutuação em decúbito ventral e dorsal, braços e per- } \\
\text { nas afastados (corpo em forma de "estrela"), pelo tempo que o } \\
\text { aluno conseguir manter a posição }\end{array}$ & 0,96 & 0,96 & 0,76 & 0,90 \\
\hline $\begin{array}{l}\text { 9. Realizar trocas de decúbito ventral/dorsal ao longo do eixo } \\
\text { longitudinal, assim como troca da posição de decúbitos pas- } \\
\text { sando pela posição grupada }\end{array}$ & 0,96 & 0,96 & 0,90 & 0,94 \\
\hline
\end{tabular}

Fonte: VASQUES, PAIXÃO E CASTRO (2021).

Pode-se verificar, no Quadro 1, que as tarefas apresentaram CVC igual (RI da tarefa 1) ou maior que 0,70. Possivelmente, as mãos em formas de concha não se mostram imprescindíveis, já que a criança poderá molhar o rosto de diversas formas. No CVCt apenas os itens 1, 2 e 7 apresentaram valores abaixo de 0,90. Em relação aos itens 2 e 7, o tempo de expiração e direção dos mergulhos podem ter influenciado na avaliação dos peritos. De modo geral, o resultado foi satisfatório, semelhante ao do estudo de Monteiro et al. (2020), no qual abordou a natação. 
Iniciação infantil ao polo aquático: fundamentação teórica e proposta de atividades Dieisson Machado Vasques • Diego Andrades Paixão • Flávio Antônio de Souza Castro

\title{
Propulsão
}

\author{
Embora respiração, equilíbrio e propulsão sejam habilidades \\ distintas, são consideradas interdependentes no processo de AMA \\ (CASTRO, CORREIA e WIZER, 2016). Dessa maneira, são descritas \\ no Quadro 2 atividades para o desenvolvimento da propulsão, in- \\ cluindo palmateios, pernadas e braçadas, nas quais o controle res- \\ piratório é peça-chave.
}

\section{Quadro 2 - Atividades de iniciação para o desenvolvimento da propulsão.}

\begin{tabular}{|c|c|c|c|c|}
\hline Atividades para ensino do palmateio propulsivo e de sustentação & CL & PP & RI & CVCt \\
\hline $\begin{array}{l}\text { 10. Realizar movimentos com as mãos submersas em forma de } \\
\text { oito (na horizontal), na posição em pé, com o objetivo de ex- } \\
\text { perimentar as forças aplicadas sobre a água no movimento } \\
\text { do palmateio }\end{array}$ & 0,96 & 0,96 & 0,83 & 0,92 \\
\hline $\begin{array}{l}\text { 11. Deslocar-se em decúbito dorsal com pernas estendidas e } \\
\text { braços posicionados no prolongamento do corpo tentando } \\
\text { realizar palmateios propulsivos a fim de deslocar o corpo na } \\
\text { direção da cabeça. De forma lúdica, o movimento das mãos } \\
\text { para "empurrar a água" pode ser comparado ao bater de } \\
\text { asas de um pequeno pássaro }\end{array}$ & 0,90 & 0,96 & 0,90 & 0,92 \\
\hline $\begin{array}{l}\text { 12. Deslocar-se em decúbito dorsal com pernas estendidas e } \\
\text { braços posicionados no prolongamento do corpo tentando } \\
\text { realizar palmateios propulsivos a fim de deslocar o corpo na } \\
\text { direção dos pés. De forma lúdica, o movimento das mãos } \\
\text { para "puxar a água" pode ser comparado a mexer duas co- } \\
\text { Iheres em panelas distintas }\end{array}$ & 0,90 & 0,96 & 0,90 & 0,92 \\
\hline $\begin{array}{l}\text { 13. Deslocar-se em decúbito ventral com as pernas estendidas e } \\
\text { rosto submerso realizando palmateio propulsivo com os bra- } \\
\text { ços posicionados acima da cabeça. De forma lúdica, o movi- } \\
\text { mento das mãos pode ser comparado a mexer duas colheres } \\
\text { em panelas distintas acima da cabeça }\end{array}$ & 0,83 & 0,96 & 0,76 & 0,85 \\
\hline $\begin{array}{l}\text { 14. Iniciar o movimento de palmateio na posição inicial em pé, } \\
\text { com cotovelos semiflexionados e palma das mãos submer- } \\
\text { sas voltadas para baixo. Aumentar a velocidade da execução } \\
\text { e, em sequência, realizar: i) inspiração seguida de breve blo- } \\
\text { queio respiratório (controle respiratório), ii) retirada dos pés } \\
\text { do fundo da piscina, iii) expiração parcial e reinício do ciclo } \\
\text { respiratório, iv) retorno à posição inicial }\end{array}$ & 0,90 & 0,96 & 0,90 & 0,92 \\
\hline $\begin{array}{l}\text { 15. Iniciar o movimento de palmateio na posição inicial em pé, } \\
\text { com cotovelos semiflexionados e palma das mãos submersas } \\
\text { voltadas para baixo. Aumentar a velocidade da execução e, } \\
\text { em sequência, realizar: i) inspiração seguida de breve bloqueio } \\
\text { respiratório voluntário (controle respiratório), ii) retirada dos } \\
\text { pés do fundo da piscina, iii) expiração parcial e reinício do ciclo } \\
\text { respiratório, iv) troca de decúbito nos planos longitudinal e } \\
\text { anteroposterior antes do retorno à posição inicial }\end{array}$ & 0,83 & 0,96 & 0,90 & 0,90 \\
\hline
\end{tabular}


Iniciação infantil ao polo aquático: fundamentação teórica e proposta de atividades Dieisson Machado Vasques • Diego Andrades Paixão • Flávio Antônio de Souza Castro

\begin{tabular}{|c|c|c|c|c|}
\hline $\begin{array}{l}\text { 16. Deslocar-se em decúbito dorsal com pernas estendidas e } \\
\text { braços posicionados para baixo, no prolongamento do corpo } \\
\text { realizando palmateio propulsivo a fim de deslocar o corpo na } \\
\text { direção da cabeça, assim como na atividade 12. Entretanto, } \\
\text { o desafio é manter uma bola próxima à sola dos pés, acom- } \\
\text { panhando o deslocamento do corpo através dos vórtices } \\
\text { formados pelo movimento da água }\end{array}$ & 0,96 & 0,96 & 0,90 & 0,94 \\
\hline $\begin{array}{l}\text { 17. Deslocar-se em decúbito ventral com as pernas afastadas e } \\
\text { joelhos levemente flexionados (perna de sapo) e rosto fora } \\
\text { d'água realizando palmateio propulsivo com os cotovelos } \\
\text { levemente flexionados e mãos posicionadas à frente da } \\
\text { cabeça. A progressão inclui a tarefa de "carregar" a bola à } \\
\text { frente do peito com o arrasto de onda gerado pelo movimen- } \\
\text { to do corpo }\end{array}$ & 0,90 & 0,96 & 0,96 & 0,94 \\
\hline \multicolumn{5}{|l|}{$\begin{array}{l}\text { Atividades para ensino da propulsão de membros inferiores e } \\
\text { superiores }\end{array}$} \\
\hline $\begin{array}{l}\text { 18. Realizar propulsão de braços e pernas simultaneamente } \\
\text { (abre e fecha) na posição sentada (polvo) e corpo submerso, } \\
\text { realizando o deslocamento em direção às costas (para trás). } \\
\text { Progressão: incluir expiração durante a execução do movi- } \\
\text { mento }\end{array}$ & 0,86 & 0,96 & 0,76 & 0,86 \\
\hline $\begin{array}{l}\text { 19. Realizar deslizes na superfície em decúbito ventral, com os } \\
\text { braços estendidos acima da cabeça e mãos sobrepostas (po- } \\
\text { sição da flecha). Progressão: realizar o deslize com o corpo } \\
\text { submerso }\end{array}$ & 0,96 & 0,96 & 0,83 & 0,92 \\
\hline $\begin{array}{l}\text { 20. Executar deslizes na superfície em decúbito ventral, com os } \\
\text { braços estendidos acima da cabeça e mãos sobrepostas (po- } \\
\text { sição da flecha), introduzindo movimento de propulsão de } \\
\text { pernas (pernada crawl). Progressão: segurar uma bola acima } \\
\text { da cabeça com as duas mãos ao invés de manter as mãos } \\
\text { sobrepostas }\end{array}$ & 0,96 & 0,96 & 0,83 & 0,92 \\
\hline $\begin{array}{l}\text { 21. Realizar deslizes na superfície em decúbito dorsal, com os } \\
\text { braços estendidos acima da cabeça e mãos sobrepostas } \\
\text { (posição da flecha) }\end{array}$ & 0,86 & 0,96 & 0,70 & 0,84 \\
\hline $\begin{array}{l}\text { 22. Executar deslizes na superfície em decúbito dorsal, com os } \\
\text { braços estendidos acima da cabeça e mãos sobrepostas } \\
\text { (posição da flecha), introduzindo movimento de propulsão } \\
\text { de pernas (pernada costas). Progressão: segurar uma bola } \\
\text { acima da cabeça com as duas mãos ao invés de manter as } \\
\text { mãos sobrepostas }\end{array}$ & 0,96 & 0,96 & 0,70 & 0,84 \\
\hline $\begin{array}{l}\text { 23. Incluir trocas de decúbito dorsal-ventral / ventral-dorsal, ao } \\
\text { longo eixo longitudinal, nas atividades } 19 \text { e } 22 \text { durante os } \\
\text { deslocamentos. Progressão: segurar uma bola acima da ca- } \\
\text { beça com as duas mãos ao invés de manter as mãos sobre- } \\
\text { postas }\end{array}$ & 0,96 & 0,90 & 0,90 & 0,92 \\
\hline
\end{tabular}


Iniciação infantil ao polo aquático: fundamentação teórica e proposta de atividades Dieisson Machado Vasques • Diego Andrades Paixão • Flávio Antônio de Souza Castro

\begin{tabular}{|c|c|c|c|c|}
\hline $\begin{array}{l}\text { 24. Introduzir rolamento do corpo ao deslocamento propulsivo } \\
\text { de pernas em decúbito ventral, na superfície, com os braços } \\
\text { posicionados ao lado do corpo. }\end{array}$ & 0,96 & 0,96 & 0,70 & 0,87 \\
\hline $\begin{array}{l}\text { 25. Realizar deslocamento propulsivo de pernas em decúbito } \\
\text { ventral, na superfície. Iniciar o movimento com o braço direi- } \\
\text { to estendido acima da cabeça e outro junto ao corpo, para } \\
\text { baixo. Já em movimento, o aluno deverá posicionar o corpo } \\
\text { a aproximadamente } 45^{\circ} \text { em relação ao fundo da piscina, de } \\
\text { maneira que um ombro fique fora da água. Executar o mes- } \\
\text { mo para o lado contrário. Inicialmente o rosto deverá estar } \\
\text { posicionado para o fundo da piscina. Progressão: introduzir } \\
\text { respiração lateral }\end{array}$ & 0,86 & 0,90 & 0,76 & 0,84 \\
\hline $\begin{array}{l}\text { 26. Acrescentar ao exercício } 25 \text { a troca entre o braço que está } \\
\text { acima da cabeça e o braço que está para baixo junto ao } \\
\text { corpo, com a consequente troca da posição entre o ombro } \\
\text { que está para fora da água e o que está para dentro. O aluno } \\
\text { contará mentalmente até } 3 \text { para realizar a troca, e assim } \\
\text { sucessivamente. Durante a troca de posição dos braços, o } \\
\text { braço que estiver à frente irá puxar e empurrar a água até se } \\
\text { posicionar junto ao corpo e para baixo. Já o braço que antes } \\
\text { estava junto ao corpo irá percorrer o trajeto até a posição } \\
\text { acima da cabeça por fora da água. Posição do rosto paralelo } \\
\text { ao fundo da piscina (nado crawl rudimentar) }\end{array}$ & 0,96 & 0,96 & 0,90 & 0,94 \\
\hline $\begin{array}{l}\text { 27. Incluir as respirações lateral (nado crawl esportivo) e frontal } \\
\text { ao exercício } 26\end{array}$ & 0,96 & 0,96 & 0,90 & 0,94 \\
\hline $\begin{array}{l}\text { 28. Executar nado crawl com a cabeça fora d'água (nado crawl } \\
\text { polo). Progressão: nadar conduzindo a bola à frente do peito, } \\
\text { através do arrasto de onda produzido pelo movimento do } \\
\text { corpo }\end{array}$ & 0,96 & 0,90 & 0,76 & 0,87 \\
\hline $\begin{array}{l}\text { 29. Realizar deslocamento propulsivo de pernas em decúbito } \\
\text { dorsal, com rolamento do corpo e braços posicionados ao } \\
\text { lado do corpo. Cabeça permanece fixa, rosto posicionado } \\
\text { para o teto }\end{array}$ & 0,96 & 0,90 & 0,76 & 0,87 \\
\hline $\begin{array}{l}\text { 30. Realizar o movimento propulsivo de pernas em decúbito } \\
\text { dorsal, com um braço estendido acima da cabeça e o outro } \\
\text { junto ao corpo, para baixo. O corpo deverá estar posicionado } \\
\text { de maneira que o ombro do braço que está para baixo fique } \\
\text { fora da água }\end{array}$ & 0,96 & 0,90 & 0,90 & 0,92 \\
\hline $\begin{array}{l}\text { 31. A partir do exercício 30, executar a troca de posição dos } \\
\text { braços de forma simultânea, de maneira que o braço posicio- } \\
\text { nado acima da cabeça puxe a água no plano frontal e o outro } \\
\text { se coloque acima da cabeça por fora da água (plano sagital), } \\
\text { com consequente troca de posição do ombro - rolamento do } \\
\text { corpo (nado costas) }\end{array}$ & 0,96 & 0,96 & 0,90 & 0,94 \\
\hline
\end{tabular}


Iniciação infantil ao polo aquático: fundamentação teórica e proposta de atividades Dieisson Machado Vasques • Diego Andrades Paixão • Flávio Antônio de Souza Castro

\begin{tabular}{|c|c|c|c|c|}
\hline $\begin{array}{l}\text { 32. Introduzir a pernada do nado peito com os alunos sentados } \\
\text { do lado de fora da piscina, fazendo-os realizar o movimento } \\
\text { com os calcanhares em contato com o solo. Progressão: rea- } \\
\text { lizar dentro da água, em decúbito ventral, segurando a bola } \\
\text { com os braços estendidos e rosto na água. Usar a bola como } \\
\text { flutuador para fazer a respiração frontal }\end{array}$ & 0,96 & 0,96 & 0,90 & 0,94 \\
\hline $\begin{array}{l}\text { 33. A partir da progressão do exercício 32, executar o desloca- } \\
\text { mento sem o apoio da bola, substituindo a mesma pelo mo- } \\
\text { vimento do palmateio, com os braços posicionados acima da } \\
\text { cabeça e rosto na água. Progressão: realizar o deslocamento } \\
\text { com a cabeça fora d'água > conduzir a bola com o arrasto de } \\
\text { onda gerado pelo deslocamento do corpo }\end{array}$ & 0,96 & 0,96 & 0,96 & 0,96 \\
\hline $\begin{array}{l}\text { 34. Executar, em decúbito dorsal, pernada do nado peito com o } \\
\text { auxílio de palmateios. Os braços deverão estar posicionados } \\
\text { para baixo, junto ao corpo }\end{array}$ & 0,96 & 0,96 & 0,76 & 0,90 \\
\hline $\begin{array}{l}\text { 35. Realizar sustentação vertical com palmateios e pernada do } \\
\text { nado peito. Partindo da posição em pé, o aluno deverá i) } \\
\text { iniciar o palmateio, ii) realizar uma inspiração seguida de } \\
\text { bloqueio respiratório, iii) retirar os pés do chão (flexão de } \\
\text { quadris e joelhos até a posição sentada) e iv) iniciar a per- } \\
\text { nada peito sem a extensão total de quadris e joelhos. Neste } \\
\text { momento o aluno iniciará respirações curtas, sem expirações } \\
\text { completas (controle respiratório) }\end{array}$ & 0,96 & 0,96 & 0,96 & 0,96 \\
\hline $\begin{array}{l}\text { 36. Introduzir a pernada alternada (eggbeater) com os alunos } \\
\text { sentados do lado de fora da piscina, fazendo-os realizar o } \\
\text { movimento com os calcanhares em contato com o solo. } \\
\text { Progressão: realizar dentro da água, em decúbito ventral, } \\
\text { segurando a bola com os braços estendidos e rosto na água. } \\
\text { Usar a bola como flutuador para fazer a respiração frontal }\end{array}$ & 0,96 & 0,96 & 0,96 & 0,96 \\
\hline $\begin{array}{l}\text { 37. Realizar sustentação vertical com palmateios e pernada } \\
\text { eggbeater. Partindo da posição em pé, o aluno deverá i) } \\
\text { iniciar o palmateio, ii) realizar uma inspiração seguida de } \\
\text { breve bloqueio respiratório voluntário, iii) retirar os pés do } \\
\text { chão (flexão de quadris e joelhos até a posição sentada) e iv) } \\
\text { iniciar a pernada eggbeater sem a extensão total de quadris e } \\
\text { joelhos. Neste momento o aluno iniciará respirações curtas, } \\
\text { sem expirações completas (controle respiratório) }\end{array}$ & 0,96 & 0,96 & 0,96 & 0,96 \\
\hline
\end{tabular}

Fonte: VASQUES, PAIXÃO E CASTRO (2021).

Verifica-se no Quadro 2 valores de CVC acima de 0,70. Apenas as tarefas 21, 22 e 24 apresentaram valores de RI igual a 0,70. O CVCt das tarefas apresentou valores entre 0,84 e 0,96. Apenas as tarefas 21, 22 e 25 apresentaram CVCt de 0,84. As tarefas 16, 17, 26, 27, 31, 32 apresentaram CVCt de 0,94, e as tarefas 33, 35, 36 e 37 CVCt de 0,96. Considerando os valores acima de 0,7 como aceitáveis (CASSEPP-BORGES, BALBINOTTI e TEODORO, 2010), pode-se 
Iniciação infantil ao polo aquático: fundamentação teórica e proposta de atividades Dieisson Machado Vasques • Diego Andrades Paixão • Flávio Antônio de Souza Castro

concluir que todas as atividades propostas foram satisfatoriamente avaliadas.

\section{Atividades técnicas}

Atividades técnicas, no ensino do PAq, são compostas por exercícios de manejo da bola, técnicas propulsivas específicas e nados adaptados para o PAq (KRÖEGER et al., 2002; CANOSSA et al., 2005; CANOSSA et al., 2009). O período de AMA dentro do processo de ensino-aprendizagem do PAq deve possuir atividades introdutórias desses exercícios específicos. A intenção, além de manter o interesse das crianças pelo PAq, é o de facilitar a transição para a próxima fase da aprendizagem.

\section{Manejo da bola: habilidades e atividades coordenativas}

Os exercícios de manipulação da bola podem ser realizados individualmente ou em pequenos grupos. A proposição dos exercícios deve estar associada às situações de jogo do PAq. Nesse sentido, sugere-se, no Quadro 3, atividades para o desenvolvimento de habilidades coordenativas. 
Iniciação infantil ao polo aquático: fundamentação teórica e proposta de atividades Dieisson Machado Vasques • Diego Andrades Paixão • Flávio Antônio de Souza Castro

\section{Quadro 3 - Atividades para o desenvolvimento de habilidades coordenativas.}

\begin{tabular}{|c|c|c|c|c|}
\hline $\begin{array}{l}\text { Manejo da bola: habilidades e atividades coordenativas indi- } \\
\text { viduais (considerar tamanho de bola adequada à criança) }\end{array}$ & CL & PP & RI & CVCt \\
\hline $\begin{array}{l}\text { 38. Na posição em pé (pés no chão): pegar a bola por baixo, } \\
\text { alternando mão direita e esquerda }\end{array}$ & 0,96 & 0,83 & 0,83 & 0,87 \\
\hline $\begin{array}{l}\text { 39. Na posição em pé (pés no chão): pegar a bola por cima, } \\
\text { afundar a mesma, e tentar pegá-la na subida para super- } \\
\text { fície }\end{array}$ & 0,96 & 0,83 & 0,83 & 0,87 \\
\hline $\begin{array}{l}\text { 40. Na posição em pé (pés no chão): pegar a bola por cima, } \\
\text { afundar a mesma, pegá-la na subida para superfície e } \\
\text { realizar uma finta }\end{array}$ & 0,96 & 0,83 & 0,96 & 0,92 \\
\hline $\begin{array}{l}\text { 41. Na posição em pé (pés no chão): pegar a bola por cima, } \\
\text { afundar a mesma, pegá-la na subida para superfície e rea- } \\
\text { lizar uma finta seguida de arremesso. O objetivo é acertar } \\
\text { um alvo (pranchas na borda da piscina, cones, goleiras } \\
\text { adaptadas, espaguetes em forma de círculo). A distância } \\
\text { inicial deve facilitar o acerto e depende da faixa etária dos } \\
\text { alunos. Sugestão: iniciar com distância entre } 3 \text { e } 5 \text { metros } \\
\text { e aumentar a medida que os alunos forem tendo êxito. } \\
\text { O exercício pode iniciar com a utilização das duas mãos } \\
\text { e progredir para apenas uma mão, fazendo com que os } \\
\text { alunos arremessem tanto com o braço direito quanto com } \\
\text { o braço esquerdo. }\end{array}$ & 0,96 & 0,83 & 0,96 & 0,92 \\
\hline \multicolumn{5}{|l|}{$\begin{array}{l}\text { Manejo da bola: habilidades e atividades coordenativas em } \\
\text { duplas (considerar tamanho de bola adequada à criança) }\end{array}$} \\
\hline $\begin{array}{l}\text { 42. Na posição em pé (pés no chão): Distantes aproximada- } \\
\text { mente } 5 \text { m, realizar passes acima da cabeça, utilizando } \\
\text { as duas mãos. Â medida que os alunos forem acertando } \\
\text { os passes, o professor deve orientar a passar a bola com } \\
\text { uma mão: posição inicial do cotovelo aproximadamente } \\
\text { na altura da orelha e bola posicionada acima e atrás da ca- } \\
\text { beça. A recepção pode ser com as duas mãos e progredir } \\
\text { para uma mão. Essa progressão vai depender principal- } \\
\text { mente da faixa etária e qualidade da recepção do passe } \\
\text { com as duas mãos (não deixar cair na água). Variação: o } \\
\text { passe, além de seco, pode ser na água, de maneira que } \\
\text { ela realize um quique antes de chegar até o companheiro. }\end{array}$ & 0,96 & 0,83 & 0,96 & 0,92 \\
\hline $\begin{array}{l}\text { 43. Na posição em pé (pés no chão): receber o passe, realizar } \\
\text { um giro no eixo longitudinal }\left(360^{\circ}\right) \text {, e realizar o passe com } \\
\text { uma das mãos para o companheiro. A recepção pode ini- } \\
\text { ciar com as duas mãos, progredindo para apenas uma das } \\
\text { mãos (respeitando o critério do exercício anterior) }\end{array}$ & 0,96 & 0,96 & 0,96 & 0,96 \\
\hline $\begin{array}{l}\text { 44. O aluno deverá iniciar o deslocamento nadando crawl } \\
\text { polo (cabeça fora d'água) ao lado do seu companheiro, } \\
\text { distantes aproximadamente } 5 \text { metros. Um deles será o } \\
\text { portador da bola e realizará o passe para o seu compa- } \\
\text { nheiro, ambos em deslocamento. Ao receber a bola, o } \\
\text { aluno deverá realizar giro ao longo do eixo longitudinal } \\
\left(360^{\circ}\right) \text { com a bola na mão e devolver o passe }\end{array}$ & 0,96 & 0,96 & 0,96 & 0,96 \\
\hline
\end{tabular}


Iniciação infantil ao polo aquático: fundamentação teórica e proposta de atividades Dieisson Machado Vasques • Diego Andrades Paixão • Flávio Antônio de Souza Castro

45. O aluno sem a bola deve nadar crawl polo até o companheiro portador da bola, distantes aproximadamente 5 metros, tocá-la com uma das mãos e retornar até a sua posição nadando costas polo, mantendo o contato visual com a bola. Neste momento, o portador da bola realizará o passe para o seu colega (com as variações possíveis já citadas anteriormente) e repetir a ação realizada por ele anteriormente

\begin{tabular}{|l|l|l|l|}
\hline 0,94 & 0,96 & 0,96 & 0,96 \\
& & & \\
\hline
\end{tabular}

Fonte: VASQUES, PAIXÃO E CASTRO (2021).

Verifica-se, no Quadro 3, que todas as tarefas apresentaram CVC acima de 0,80. As tarefas 38, 39, 40, 41 e 42 apresentaram CVC para PP de 0,83, e as demais, 0,96. Ainda, apenas as tarefas 38 e 39 apresentaram CVC para RI de 0,83, e as demais, 0,96. No geral, o CVCt apresentou valores de 0,87 a 0,96, desse modo, pode-se concluir que as atividades para o desenvolvimento de habilidades coordenativas foram avaliadas de modo satisfatório.

\section{Técnicas propulsivas específicas e nados combinados}

As técnicas propulsivas permitem ao jogador obter o domínio do seu corpo no meio aquático de maneira refinada e eficiente. De acordo com Canossa et al. (2005), destacam-se no processo de ensino-aprendizagem: (i) nado crawl com cabeça fora d'água (crawl polo); (ii) nado costas polo; (iii) nado costas com pernada peito; (iv) nado crawl polo com mudanças de direção; (v) exercícios de arranque e travagem; (vi) mudanças de direção e sentido do nado; (vii) eggbeater nas posições vertical, horizontal, oblíqua, frontal, lateral e de costas; (viii) inversão (pêndulos): simples ou com rotação ventral/dorsal e dorsal/ventral.

\section{Atividades de iniciação para o desenvolvimento de aspectos tático-técnicos}

Segundo Canossa et al. (2009), as atividades de aproximação ao jogo têm como finalidade, além da fixação dos gestos técnicos, 
o aprimoramento das principais ações realizadas pelos jogadores durante as partidas. São atividades que buscam ampliar o repertório de ações das crianças, contribuindo, assim, para as tomadas de decisões nos jogos. De maneira geral, são exercícios compostos por deslocamentos com bola, progressão em direção à meta e finalização, tais como: (i) crawl polo seguido de arremesso para o alvo (pranchas, cones, cestas); (ii) crawl polo seguido de arremesso para o gol (sem e com goleiro); (iii) crawl polo em velocidade, trocar para a costas polo, receber o passe e arremessar para o gol de frente e revés (sem e com goleiro); (iv) crawl polo executando fintas e giros sobre o adversário (1x1), seguido de arremesso para o gol (sem e com goleiro); (v) crawl polo atacando em superioridade numérica (2x1), seguido de arremesso para o gol (sem e com goleiro).

Os exercícios tático-técnicos devem conter organização (estratégia), tomadas de decisões e jogos situacionais (BAYER, 1994; KRÖEGER et al., 2002; GRECO, 2012; GALLATI, 2017). A organização diz respeito ao que foi previamente combinado e/ou treinado, como as regras do jogo (formal ou adaptado), às posições básicas defensiva e ofensiva e aos métodos de jogo defensivo e ofensivo (GRÉHAIGNE e GUILLON, 1992; CANOSSA et al., 2009). O PAq se desenvolve em um conjunto de interações com os companheiros de equipe ou adversários, motivo pelo qual requer constante adaptação dos jogadores envolvidos (RIERA, 1995).

As atividades ou jogos situacionais devem ser incluídos nos planos de aula (GRECO, 2012; KRÖEGER et al., 2002). No sentido de desenvolver e/ou fortalecer a capacidade de jogo geral, deve-se destacar os elementos táticos ofensivos e defensivos (KRÖEGER et al., 2002). Quanto aos elementos táticos ofensivos, podemos destacar, segundo Kröeger et al. (2002): i) acertar o alvo (relacionado com o objeto), ii) transportar a bola ao objetivo (relacionado ao objetivo), iii) obter vantagem tática do jogo (relacionado com o adversário), iv) jogar coletivamente (relacionado com o companheiro), v) reconhecer espaços (relacionado com o adversário), vi) superar o adversário (relacionado com o adversário) e vii) oferecer-se e orientar-se (relacionado com o meio ambiente). 
Iniciação infantil ao polo aquático: fundamentação teórica e proposta de atividades Dieisson Machado Vasques • Diego Andrades Paixão • Flávio Antônio de Souza Castro

Por outro lado, os elementos táticos defensivos visam justamente impedir que os elementos ofensivos ocorram. Esses elementos visam (BAYER, 1994; KRÖEGER et al., 2002; GALLATI, 2017): i) proteger a meta defendida (relacionado com o objetivo), ii) impedir progressão (relacionado com o objetivo), iii) reduzir espaços (relacionado com o meio ambiente), iv) induzir ao erro (relacionado com o adversário), v) realizar cobertura defensiva (relacionado com o companheiro e meio ambiente), vi) manter a concentração utilizando os referenciais da bola, meta e adversários para o correto posicionamento (relacionado com o objetivo, adversários e meio ambiente) e vii) recuperar a posse da bola (relacionado ao objetivo).

\section{Propostas de jogos situacionais}

O presente estudo propõe jogos situacionais com o objetivo de facilitar o desenvolvimento de atributos para a prática do PAq de maneira lúdica. O Quadro 4 apresenta propostas de jogos situacionais.

\section{Quadro 4 - Propostas de jogos situacionais}

\begin{tabular}{|c|c|c|c|c|}
\hline & CL & PP & RI & $\mathrm{CVCt}$ \\
\hline $\begin{array}{l}\text { 46. Bola no arco: cada equipe na sua linha de fundo, pode } \\
\text { se ordenar na forma que desejar. A uma distância de } \\
\text { três metros, aproximadamente, atrás da linha de fun- } \\
\text { do encontram-se dois jogadores da equipe adversária, } \\
\text { cada um com um arco na mão. Cada equipe deve passar } \\
\text { entre si a bola, avançando para o setor adversário de } \\
\text { forma a colocar um jogador em posse de bola em con- } \\
\text { dição de lançar acertando o arco que o colega tem na } \\
\text { sua mão. Variação: o jogador de posse da bola não pode } \\
\text { tocar os pés no chão. Combinações importantes: apenas } \\
\text { interceptar o passe }\end{array}$ & 0,96 & 0,96 & 0,96 & 0,96 \\
\hline $\begin{array}{l}\text { 47. Quatro metas: em um campo de jogo são colocadas } \\
\text { quatro metas (por exemplo, arcos, cones, pranchinhas } \\
\text { na vertical na borda da piscina), e cada equipe em posse } \\
\text { de bola deve procurar acertar os alvos colocados. Varia- } \\
\text { ções: o jogador de posse da bola não poderá tocar os } \\
\text { pés no chão, pré-determinar o número de passes ao in- } \\
\text { vés do tempo de posse }\end{array}$ & 0,96 & 0,96 & 0,90 & 0,94 \\
\hline
\end{tabular}


Iniciação infantil ao polo aquático: fundamentação teórica e proposta de atividades Dieisson Machado Vasques • Diego Andrades Paixão • Flávio Antônio de Souza Castro

\begin{tabular}{|c|c|c|c|c|}
\hline $\begin{array}{l}\text { 48. Soma de passes: Duas equipes tentam pegar a bola, cada } \\
\text { uma procura passar a bola entre si a maior quantidade } \\
\text { de vezes possível. O time adversário procura intercep- } \\
\text { tar ou antecipar a bola e pegá-la. O jogador de posse da } \\
\text { bola, ao realizar o passe, pode propor um cálculo mate- } \\
\text { mático simples ao companheiro que irá receber a bola. } \\
\text { Ex.: } 2 \text { + } 2 \text {. Ao receber o passe, o companheiro responde } \\
\text { e propõe um cálculo ao próximo. Variações: realizar o } \\
\text { passe com as duas mãos, progredindo para o passe com } \\
\text { apenas uma mão (explorar a multilateralidade); o joga- } \\
\text { dor com posse da bola não poderá tocar os pés no chão; } \\
\text { nenhum jogador poderá tocar os pés no chão. Combi- } \\
\text { nações: pode ser por tempo, por exemplo, cada equipe } \\
\text { tem } 1 \text { minuto para trocar a maior quantidade de passes } \\
\text { possível, enquanto a outra tenta interceptar }\end{array}$ & 0,96 & 0,96 & 0,96 & 0,96 \\
\hline 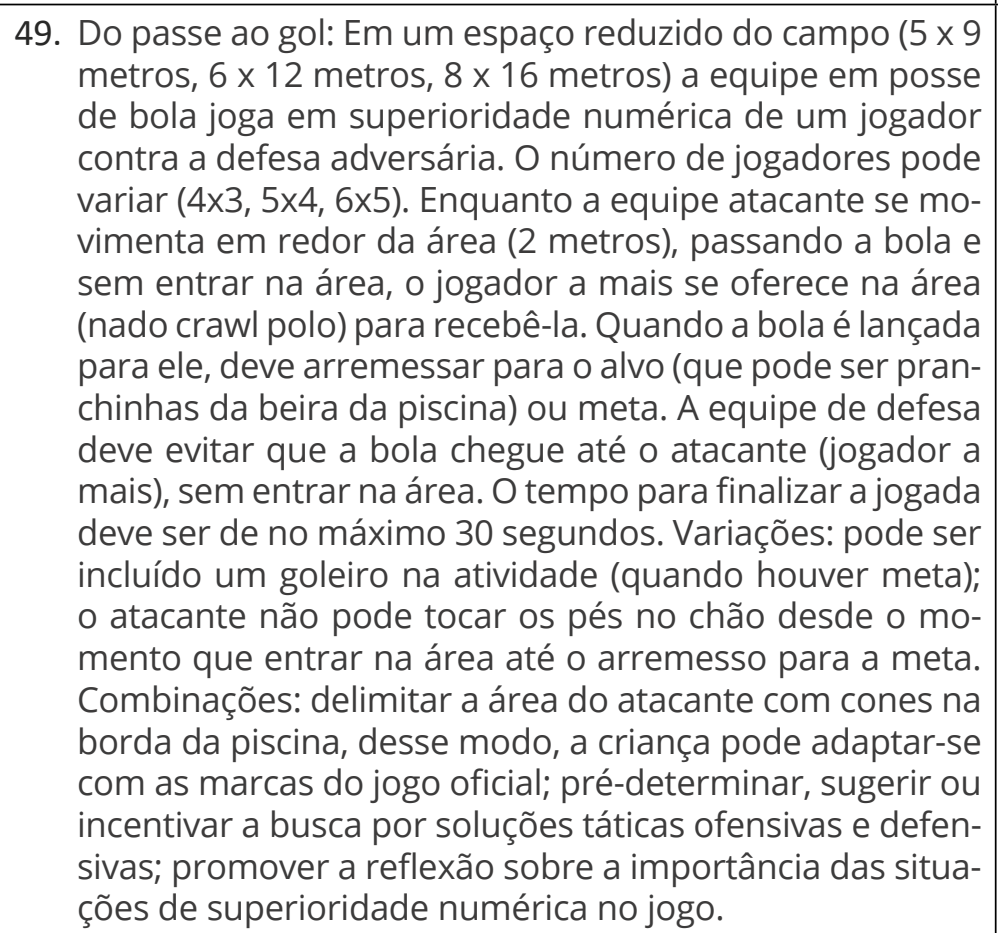 & 0,96 & 0,96 & 0,96 & 0,96 \\
\hline $\begin{array}{l}\text { 50. Coringa: Duas equipes compostas por } 3 \text { jogadores cada, } \\
\text { em um campo de } 9 \text { × } 9 \text { metros, tendo como meta golei- } \\
\text { ra, cones ou pranchas apoiadas uma na outra vertical. } \\
\text { Haverá um quarto jogador, o Coringa, que jogará a favor } \\
\text { da equipe que estiver com a posse da bola, provocando } \\
\text { uma situação de superioridade numérica. No momento } \\
\text { em que a bola troca de posse este jogador passa a apoiar } \\
\text { a outra equipe imediatamente, estimulando também as } \\
\text { tomadas de decisão nas transições ofensiva/defensiva e } \\
\text { defensiva/ofensiva (contra-ataques). Para facilitar o an- } \\
\text { damento da atividade, este jogador poderá usar touca } \\
\text { vermelha, por exemplo. A fim de manter a qualidade do } \\
\text { jogo, o professor deverá promover intervalos de } 1 \text { minu- } \\
\text { to a cada dois ataques de cada equipe }\end{array}$ & 0,96 & 0,96 & 0,96 & 0,96 \\
\hline
\end{tabular}

Fonte: VASQUES, PAIXÃO E CASTRO (2021). 
Verifica-se no Quadro 4 que todas as tarefas apresentam CVC acima de 0,90. Apenas a tarefa 47 apresenta CVC para RI de 0,90, e a média de 0,94, ou seja, ainda um valor de destaque. O CVCt geral da lista de tarefas foi de 0,91. A média final pode ser considerada de grande relevância para a proposta do estudo. Portanto, é possível afirmar que as atividades para a iniciação infantil no PAq possuem clareza de linguagem, pertinência prática e representatividade.

\section{Considerações finais}

O presente estudo buscou propor diretrizes teórico-práticas para a iniciação infantil ao PAq. As atividades propostas possuem clareza de linguagem, pertinência prática e representatividade. Motivado pela escassez na literatura em relação ao tema, este estudo pretende servir como base para intervenções e programas na área. As atividades visam o incremento do repertório motor pelo desenvolvimento das habilidades aquáticas, manejo da bola e técnicas propulsivas específicas (COSTA et al., 2012; CANOSSA et al., 2009). Por fim, esta proposta pretende ainda provocar discussões acerca dos métodos de ensino do PAq, contribuindo para a construção de metodologias de ensino que possam ser facilmente transferidas para a borda das piscinas.

\section{Referências}

BAELLA, O. e LLORET, M.: El water polo en la escuela: del juego al deporte. INEFC, Centre de Barcelona (eds). Universitat de Barcelona, 1996.

BAKER, J.; CÔTÉ, J.; ABERNETHY, B.; Sport-specific practice and the development of expert decision-making in team ball sports. Journal of Applied Sport Psychology, 15, 12-25, 2003. doi:10.1080/1041320039018003 
Iniciação infantil ao polo aquático: fundamentação teórica e proposta de atividades Dieisson Machado Vasques • Diego Andrades Paixão • Flávio Antônio de Souza Castro

BAYER, C. O Ensino dos Desportos Coletivos. Editions Vigot, Paris, 1994.

CANOSSA, S.; FERNANDES, R.; CARMO, C.; ANDRADE, A.; SOARES, S.; Ensino multidisciplinar em natação: reflexão metodológica e proposta de lista de verificação. Motricidade, Portugal, p. 82-99, 2007.

CANOSSA, S.; GARGANTA, J.; FERNANDES, R. PAQ: Conteúdos de ensino e princípios do jogo. Porto, p.07-29, set. 2009.

CASSEPP-BORGES, V.; BALBINOTTI, M. A. A.; TEODORO, M. L. M. Tradução e validação de conteúdo: uma proposta para a adaptação de instrumentos. In: PASQUALI, L. e colaboradores. Instrumentação psicológica: fundamentos e práticas. Porto Alegre: Artmed, 2010. p. 506-520

CASTRO, F. A. S.; WIZER, R.; CORREIA R. Adaptação ao meio aquático: características, forças e restrições. Natação e Atividades Aquáticas: Pedagogia, Treino e Investigação. 1ed. Leiria: Escola Superior de Educação e Ciências Sociais, Instituto Politécnico de Leiria. v. 1, p. 13-26. 2016.

CATTEAU, R.; GAROFF, G. 0 ensino da natação. São Paulo: Editora Manole LTDA, 1990.

COSTA, A. M.; MARINHO, D. A.; ROCHA, H.; SILVA, A. J.; BARBOSA, T. M.; FERREIRA, S.; MARTINS, M. Deep and shallow water effects on developing preschooler's aquatic skills. Journal of Human Kinetics, vol. 32, pp. 211-219, 2012.

CLÉMENÇON, J. P. Une situation nouvelle. In.: EPS., (218): 47-48, 1989.

FERNANDES, J. R. P.; LOBO DA COSTA, P. H. Pedagogia da natação: um mergulho para além dos quatro estilos. Revista Brasileira de Educação Física e Esportes, São Paulo, v.20, n.1., p. 5-14, jan/ mar 2006.

FIORI, J. M.; TEIXEIRA, L. B. T.; WIZER, R. T.; CASTRO, F. A. Pedagogia da natação: análise das atividades realizadas em aulas para crianças. Pensar a Prática, Goiânia, v. 22, 2019. 
Iniciação infantil ao polo aquático: fundamentação teórica e proposta de atividades Dieisson Machado Vasques • Diego Andrades Paixão • Flávio Antônio de Souza Castro

FREIRE, P. Pedagogia da autonomia: saberes necessários à prática educativa. 50ª ed. Rio de Janeiro, 2015.

GALATTI, R. O ensino dos jogos esportivos coletivos: avanços metodológicos dos aspectos estratégico-tático-técnicos. Pensar a Prática, Goiânia, v. 20, n. 3, 2017.

GALLAHUE, D.; OZMUN, J.; GOODWAY, J. Compreendendo o desenvolvimento motor: bebês, crianças, adolescentes e adultos. AMGH Editora, 2013.

GONZALEZ, J. F. Sistema de classificação de esportes com base nos critérios: cooperação, interação com o adversário, ambiente, desempenho comparado e objetivos táticos da ação. Revista Digital, Buenos Aires, 2004.

GONZÁLEZ, F. J.; DARIDO, S. C.; OLIVEIRA, De. A. Esportes de invasão: basquetebol, futebol, futsal, handebol, ultimate frisbee. 2. edição ed. Maringá: Eduem - Editora da Universidade Estadual de Maringá, 2017.

GRECO, P. J. Metodologia do ensino dos esportes coletivos: iniciação esportiva universal, aprendizado incidental-ensino intencional. Revista Mineira de Educação Física, Belo Horizonte, v. 20, n. 1, p. 145-174, 2012.

GRÉHAIGNE, J. F.; GUILLON, R. L'utilisation des jeux d'opposition a l'école. Revue de I'Education Physique, v. 32, n. 2, p. 51-67, 1992.

HERNÁNDEZ-NIETO, R. Instrumentos de recolección de datos en ciencias sociales y ciencias biomédicas. Universidad de los Andes, Consejo de Estudios de Postgrado, Venezuela, v. 1, p. 116121, 2011.

KRÖGER, C.; ROTH, K.; MEMMERT, D. Escola da bola: um ABC para iniciantes nos jogos esportivos. São Paulo: Phorte, 2002. LAMAS, L., BARRERA J., OTRANTO G \& UGRINOWITSCH C. Invasion team sports: strategy and match modeling. International Journal of Performance Analysis in Sport, 14:1, 307-329, 2014 
MONTEIRO, G. N.; RIBAS, S.; JIMÉNEZ, F. J.; MAZZARDO, T.; ARAÚJO, N. D.; ABURACHID, L. M. C. Development process of content validity of pedagogical knowledge assessment in swimming, Rev. Bras. Cineantropom. Hum., Florianópolis, v. 22, 2020. PALMER, M. A Ciência do Ensino da Natação. São Paulo: Manole, 1990.

RIERA, J. R. Estratégia, táctica y técnica deportivas. Apunts, Barcelona, n. 39, p. 45-56, 1995.

SARMENTO, J. P. Estudo histórico da introdução desenvolvimento e desaparecimento do Pólo aquático em Portugal no período compreendido entre 1907 e 1952. Antologia de Textos. Desporto e Sociedade. Lisboa, 1989.

SCHNEIDER, P; MEYER, F. Avaliação antropométrica e da força muscular em nadadores pré-púberes e púberes. Revista Brasileira de Medicina do Esporte, Niterói, vol. 11, n. 4, julho/ agosto de 2005.

SILVA, L M; GIULIANO, A F; CASTRO, F A de S. Ensino, aprendizagem e avaliação da técnica do eggbeater em aulas de natação. Revista Brasileira de Ciência e Movimento, Porto Alegre, vol. 24, n.2, p. 138-145, 2016

SMITH, H. K. Applied Physiology of Water Polo: Review Article. Sports Medicine: Department of Sport and Exercise Science, The University of Auckland, Auckland, New Zealand, Auckland, v. 334, n. 317, p. 317-334, nov. 1998.

TUCHER, G. Relação entre a origem do arremesso e a ocorrência do gol em competição no polo aquático masculino. Revista Brasileira de Cineantropometria e Desempenho Humano, Florianópolis, vol. 16, n.2, p. 136-143, 2014.

WEINECK, J. Treinamento ideal. 9.ed. São Paulo: Editora Manole, 1999. 
Iniciação infantil ao polo aquático: fundamentação teórica e proposta de atividades Dieisson Machado Vasques • Diego Andrades Paixão • Flávio Antônio de Souza Castro

\title{
Publisher
}

\begin{abstract}
Universidade Federal de Goiás. Faculdade de Educação Física e Dança. Publicação no Portal de Periódicos UFG. As ideias expressadas neste artigo são de responsabilidade de seus autores, não representando, necessariamente, a opinião dos editores ou da universidade.
\end{abstract}

